\title{
Reexamination of moment tensors for initial motion of explosion earthquakes using borehole seismograms at Sakurajima volcano, Japan
}

\author{
Takeshi Tameguri, Masato Iguchi, and Kazuhiro Ishihara
}

Sakurajima Volcano Research Center, Disaster Prevention Research Institute, Kyoto University, Sakurajima, Kagoshima 891-1419, Japan

(Received January 31, 2000; Revised October 23, 2000; Accepted October 23, 2000)

\begin{abstract}
We estimated the seismic moment tensor for the initial phase of explosion earthquakes associated with Vulcanian explosions at the andesitic volcano Sakurajima. We applied a waveform inversion method to 24 events observed with borehole seismometers at 6 stations assuming a single triangular source time function. The three diagonal components representing volumetric change were dominant in the estimated moment tensors. The three diagonal components were positive and had almost the same values with the difference among them less than $10 \%$ for most of the explosion earthquakes, while non-diagonal components were negligibly small compared with the diagonal ones. Durations of source time functions had a range of $0.2-0.5 \mathrm{~s}$ and seismic moments were $10^{11} \sim 10^{12} \mathrm{Nm}$. We conclude that the explosion earthquakes are initiated by an isotropic expansion.
\end{abstract}

\section{Introduction}

Explosive eruptions of Vulcanian style often accompany explosion earthquakes at andesitic volcanoes. Seismograms of these explosion earthquakes generally show compressional initial motions at all stations and $S$-phases are not clearly recorded (Minakami, 1974). Sakurajima volcano repeated flank eruptions and summit eruptions during historical time. A large flank eruption occurred in 1914. The latest eruptive activity at the summit crater began in October 1955 and explosive eruptions have frequently occurred at the summit crater, producing more than 7400 explosive eruptions as of the end of 1999. The hypocenters of explosion earthquakes are located at depths of 1 to $3 \mathrm{~km}$ beneath the summit crater (e.g. Nishi, 1976). The hypocentral zone corresponds to a cylindrical conduit with radius of $200 \mathrm{~m}$ as revealed by Ishihara (1988) and Iguchi (1994). The initial motions of explosion earthquakes are compressions at all the stations with epicentral distances of 1.5 to $50 \mathrm{~km}$. This observation suggests expansion in both upper and lower hemispheres of the source (Yamasato, 1987).

Recently, the source mechanisms of explosion earthquakes at Sakurajima volcano have been investigated by evaluating moment tensor components. Iguchi (1994) using the amplitude distribution of $P$-wave first motions proposed a vertical expansion model dominated by a vertical dipole. Uhira and Takeo (1994) and Uhira et al. (1995) used waveform inversions to obtain the source process of explosion earthquakes, and showed that an explosion earthquake is initiated by small and vertical expansion and followed by large and horizontal contraction at the source.

Recording of earthquakes on the ground surface at Sakurajima is complicated by artificial noise sources, such as

Copy right (C) The Society of Geomagnetism and Earth, Planetary and Space Sciences (SGEPSS); The Seismological Society of Japan; The Volcanological Society of Japan; The Geodetic Society of Japan; The Japanese Society for Planetary Sciences. traffic and Sabo dam construction, and surface layers formed by pumice and ash at Sakurajima volcano (Iguchi, 1995). Furthermore, a delay of the onset of the horizontal components with respect to the vertical one is observed (Fig. 1). The noise and delay of onset times of the horizontal components affect the determination of moment tensor components, which presents problems in previous studies that have used records from seismometers installed on the ground surface. The previous studies about the source mechanism of explosion earthquakes have also been limited to the analysis of only a few events. In this study, we applied the method of waveform inversion to 24 explosion earthquakes recorded by borehole seismometers in 1995-1997, following the completion of a borehole seismometer network in 1994. Our analyses focus on evaluating moment tensor components of the initial part which is not influenced by the following contraction process as shown by Uhira and Takeo (1994).

\section{Observation and Data}

The active crater of Sakurajima volcano is surrounded with 10 permanent seismic stations operated by Sakurajima Volcano Research Center (SVRC), Kyoto University (Fig. 2). At 8 stations, three-component short-period seismometers $\left(T_{0}=1 \mathrm{~s}\right)$ are installed in boreholes at the depths of 85 to $355 \mathrm{~m}$. The other 2 stations are equipped with seismometers installed on the surface in vaults. Seismic signals from the stations are transmitted to SVRC via telephone lines or radio and recorded as velocity waveform with a sampling rate of $100 \mathrm{~Hz}$.

Figure 1(a) shows an example of waveforms from an explosion earthquake observed by the borehole seismometer at Harutayama (HAR), $2.8 \mathrm{~km}$ from the crater, compared with waveforms recorded by a seismometer installed on the ground surface. Harutayama is a lava dome covered with a pumice and ash layer $25 \mathrm{~m}$ thick. The borehole seismometer is installed at a depth of $290 \mathrm{~m}$ in the lava dome and the 
(a) borehole

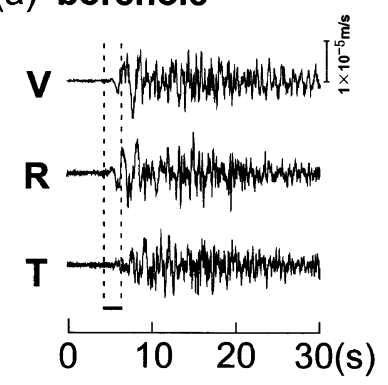

(b) borehole

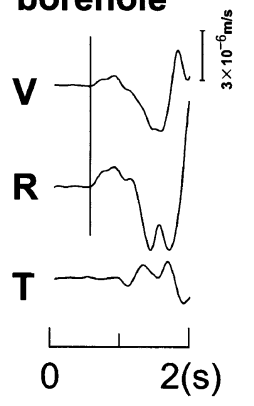

ground

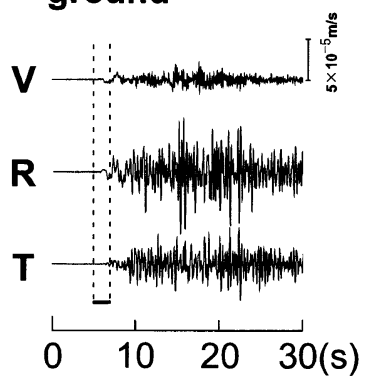

(c) ground

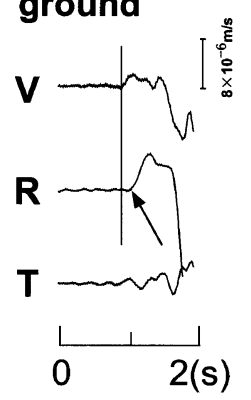

Fig. 1. Velocity waveforms of an explosion earthquake at 01:26, June 7, 1998, recorded at station HAR. The three traces are vertical, radial, and transverse components, from top to bottom. (a) Records of borehole seismometer $\left(T_{0}=1 \mathrm{~s}\right)$ and seismometer installed on the ground surface. (b) Magnified portion shown by dashed lines in (a) of borehole seismogram. (c) Enlargement of seismograms recorded on the ground surface.

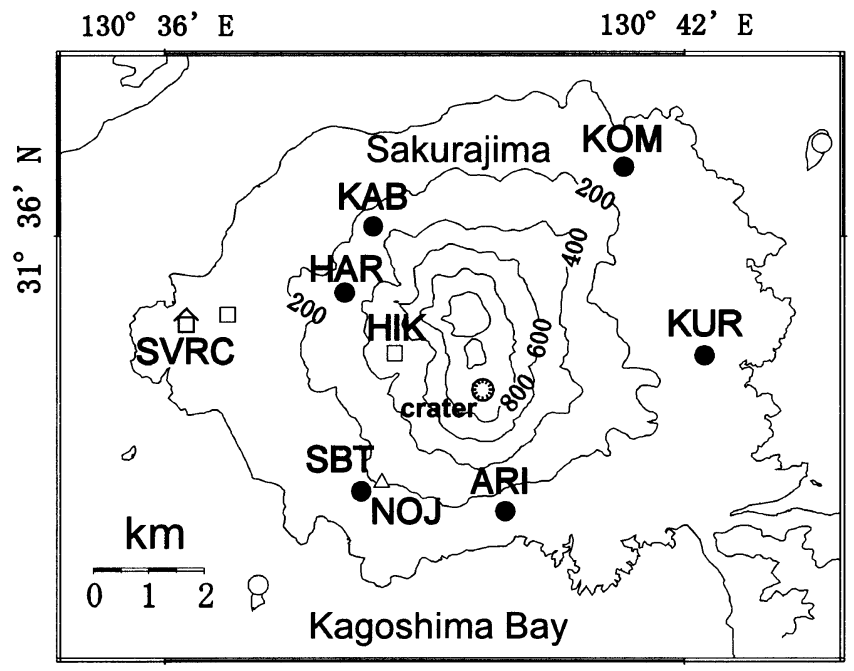

Fig. 2. Seismic stations operated by the Sakurajima Volcano Research Center. Circles and squares denote permanent borehole and surface seismic stations, respectively. Solid circles indicate stations used for analysis in this study. The station NOJ was temporarily installed.

surface seismometer was temporally installed on the pumice and ash layer. The seismograms observed on the ground surface, especially the horizontal components, are dominated by higher frequencies $(4 \mathrm{~Hz})$, while the borehole records are dominated by frequencies of $2 \mathrm{~Hz}$ in the initial portion. In seismograms from the surface seismometer, the onset of delay of $0.2 \mathrm{~s}$ between the vertical and radial components was

observed, as shown by the arrow in Fig. 1(c), while no such a delay was detected in the record from borehole seismometer as expected from usual $P$-waves propagating from the summit crater (Fig. 1(b)). A time lag of $0.3 \mathrm{~s}$ for the onset time is also observed at station HIK. The time lag is also observed for regional tectonic earthquakes. We think that the lag is caused by the unconsolidated pumice and ash layer near the ground surface. Since the time lag of the first motion between the radial and vertical components exerts serious influence on the waveform inversion analysis, only the records from borehole seismometers at 6 stations, denoted by solid circles in Fig. 2, were used for the evaluation of the moment tensor.

\section{Analysis}

We analyzed 24 events out of 404 explosion earthquakes that occurred during the period from 1995 to 1997 (Sakurajima Volcano Research Center, Disaster Prevention Research Institute, Kyoto University, 1999). The hypocenters of the explosion earthquakes were determined from $P$ wave arrival times at 10 permanent stations, assuming a homogeneous half-space with $V_{P}=2.5 \mathrm{~km} / \mathrm{s}$. The hypocenters were located in a narrow cylindrical zone with radius of $200 \mathrm{~m}$ at depths from 2 to $3 \mathrm{~km}$ beneath the summit crater, as shown in the previous study (Iguchi, 1994). The hypocenter locations are used for calculation of Green's functions used in the waveform inversion analysis.

Green's functions were calculated by the method of Takeo (1985) using the reflection-transmission matrices (Kennett and Kerry, 1979) and a discrete wavenumber method (Bouchon, 1981), including the effect of an anelastic medium. A homogeneous half-space with $V_{P}=2.5 \mathrm{~km} / \mathrm{s}$, $Q_{P}=20$, and a density of $2.5 \times 10^{3} \mathrm{~kg} / \mathrm{m}^{3}$ (Iguchi, 1994) was assumed for calculation of Green's function.

In order to remove amplifications due to local site effects around each station, waveform amplitudes were corrected by site amplification factor, which is defined as amplitude ratios of $P$-wave first motions of teleseismic earthquakes from many directions, to reference station (Iguchi, 1994). Station KUR, which is distant from the active crater and the deepest borehole station was used as a reference site. Teleseismic events whose dominant frequency of $P$-waves was near $2 \mathrm{~Hz}$ were used considering spectra of explosion earthquake. The site correction factor, which is inverse of amplification factor, and the standard deviation at borehole stations ARI, SBT, HAR, KAB, and KOM to KUR station were $0.54 \pm 0.08,0.89 \pm 0.28,1.26 \pm 0.39,0.73 \pm 0.23$, and $0.85 \pm 0.26$, respectively. Waveforms were low-pass filtered at $5 \mathrm{~Hz}$ to remove short-period noise.

Moment tensors were evaluated by waveform inversion using a method based upon Kikuchi and Kanamori (1991). Synthetic seismograms $s_{j}(t)$ are represented as

$$
s_{j}(t)=\sum_{n=1}^{N_{b}} a_{n} w_{j n}(t ; p),
$$

where $N_{b}$ is the number of elementary tensors and $w_{j n}(t ; p)$ denote the synthetic waveform at the $j$-th station due to the $n$-th elementary tensor with parameter $p$ that collectively represents the onset time, the location, and the source time function. The coefficients $a_{n}$ are related to the 6 elementary 
(a)

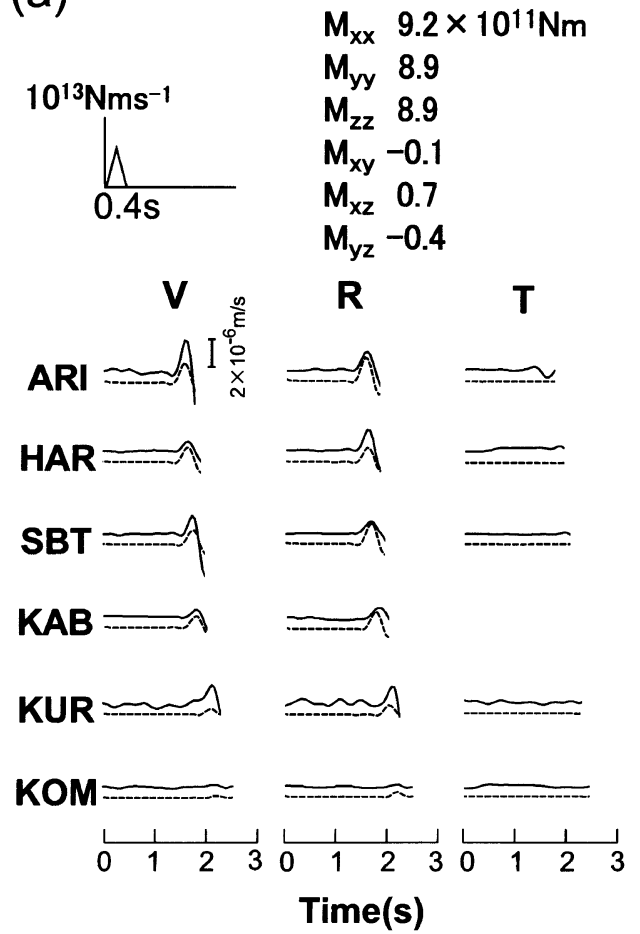

(b)

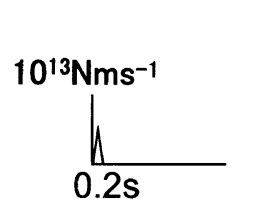

$M_{x x} 3.9 \times 10^{11} \mathrm{Nm}$

$M_{\mathrm{yy}} 3.8$

$M_{\mathrm{zz}} 4.0$

$M_{x y}-0.2$

$\mathrm{M}_{\mathrm{xz}} 0.5$

$M_{\mathrm{yz}}-0.2$

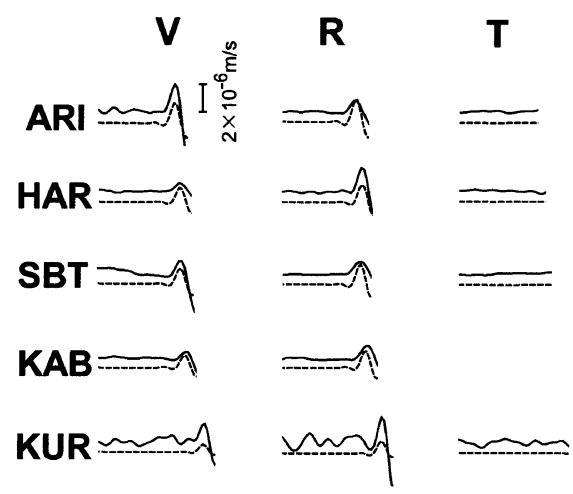

$\mathrm{KOM} \sim$

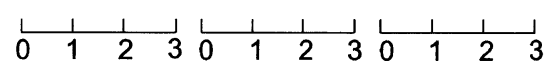

Time(s)

Fig. 3. Results of a waveform inversion using 6 borehole stations. (a) 03:15, January 8, 1995 (No. 3). (b) 08:50, February 27, 1996 (No. 18). These events were not recorded at KAB_T, KOM_R, and KOM_T. Solid and broken traces indicate observed and synthetic waveforms, respectively. Waveforms of vertical, radial, and transverse components are plotted from left to right. The triangular source time functions are displayed in the upper left and obtained moment tensor components are shown in the upper right.

moment tensor and are obtained by minimizing the square of the difference between the synthetic and observed velocity seismograms. Using the coefficients $a_{n}$, the resultant moment tensor is given by

$$
M=\left[\begin{array}{ccc}
a_{2}-a_{5}+a_{6} & a_{1} & a_{4} \\
a_{1} & -a_{2}+a_{6} & a_{3} \\
a_{4} & a_{3} & a_{5}+a_{6}
\end{array}\right] .
$$

Source time functions related to the parameter $p$ were assumed to be triangular shapes as shown in Fig. 3. The rise time and duration of the source time functions were determined by changing the values from $0.05 \mathrm{~s}$ to $1 \mathrm{~s}$ with increments of $0.05 \mathrm{~s}$ for minimizing the residuals.

\section{Results}

Two examples of the results of the waveform inversion are shown in Fig. 3. The synthetic waveforms fit well the observed first motions of the vertical and radial components at all the stations. The three diagonal components $\left(M_{x x}\right.$, $M_{y y}$, and $M_{z z}, x$ : north, $y$ : east, and $z$ : downward) in the moment tensor for the explosion earthquake on January 8 , 1995 were positive and had nearly equal values of $9 \times 10^{11}$ $\mathrm{Nm}$. The non-diagonal components were smaller by 2 orders of magnitude. The rise time and duration of the source time function are $0.2 \mathrm{~s}$ and $0.4 \mathrm{~s}$, respectively. Similar results were obtained for the earthquake on February 27, 1996. The three diagonal components were $4 \times 10^{11} \mathrm{Nm}$, and the duration of the source time function is $0.2 \mathrm{~s}$. The moment tensor components obtained for the 24 events are listed in Table 1. (a)

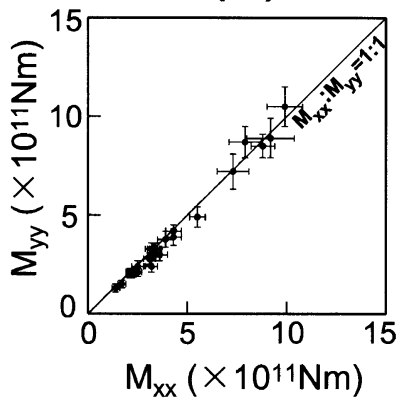

(c)

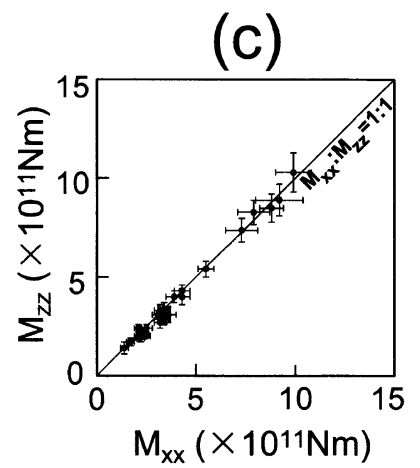

Fig. 4. Relation among three diagonal components and errors in 24 events. (a) $M_{x x}$ versus $M_{y y}$. (b) $M_{z z}$ versus $M_{y y}$. (c) $M_{x x}$ versus $M_{z z}$. (b)

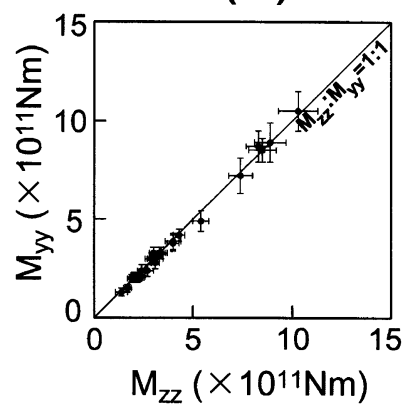


Table 1. Moment tensor components and errors, and rise time and duration of source time functions.

\begin{tabular}{|c|c|c|c|c|c|c|c|c|c|c|c|}
\hline No & Date & Time & $\begin{array}{l}\text { Depth } \\
(\mathrm{km})\end{array}$ & $M_{x x}$ & $M_{y y}$ & $M_{z z}$ & $M_{x y}$ & $\begin{array}{l}M_{x z} \\
\quad\left(\times 10^{11}\right.\end{array}$ & $\begin{array}{l}M_{y z} \\
\mathrm{Nm})\end{array}$ & $\begin{array}{l}\text { Rise time } \\
\text { (s) }\end{array}$ & $\begin{array}{l}\text { Duration } \\
\text { (s) }\end{array}$ \\
\hline 1 & Jan. 01, 1995 & $14: 50$ & 2.86 & $3.2 \pm 0.3$ & $3.3 \pm 0.3$ & $3.3 \pm 0.3$ & $-0.2 \pm 0.0$ & $0.3 \pm 0.0$ & $-0.0 \pm 0.0$ & 0.10 & 0.20 \\
\hline 2 & Jan. 03, 1995 & 10:01 & 2.08 & $3.1 \pm 0.3$ & $2.8 \pm 0.3$ & $3.1 \pm 0.2$ & $-0.2 \pm 0.0$ & $0.1 \pm 0.0$ & $0.0 \pm 0.0$ & 0.10 & 0.20 \\
\hline 3 & Jan. 08, 1995 & $03: 15$ & 2.48 & $9.2 \pm 1.2$ & $8.9 \pm 1.0$ & $8.9 \pm 0.8$ & $-0.1 \pm 0.0$ & $0.7 \pm 0.1$ & $-0.4 \pm 0.0$ & 0.20 & 0.40 \\
\hline 4 & Jan. 24, 1995 & 09:03 & 2.19 & $3.4 \pm 0.3$ & $3.0 \pm 0.3$ & $2.9 \pm 0.3$ & $0.1 \pm 0.0$ & $0.4 \pm 0.0$ & $0.1 \pm 0.0$ & 0.10 & 0.20 \\
\hline 5 & May 14, 1995 & 20:14 & 2.69 & $1.4 \pm 0.2$ & $1.3 \pm 0.2$ & $1.4 \pm 0.3$ & $-0.0 \pm 0.0$ & $0.4 \pm 0.0$ & $-0.2 \pm 0.0$ & 0.10 & 0.20 \\
\hline 6 & May 17, 1995 & $07: 52$ & 2.40 & $2.5 \pm 0.3$ & $2.4 \pm 0.3$ & $2.4 \pm 0.2$ & $-0.2 \pm 0.0$ & $0.2 \pm 0.0$ & $0.2 \pm 0.0$ & 0.10 & 0.20 \\
\hline 7 & Aug. 03, 1995 & $16: 32$ & 2.47 & $9.9 \pm 0.9$ & $10.5 \pm 1.0$ & $10.0 \pm 1.0$ & $0.9 \pm 0.0$ & $0.2 \pm 0.0$ & $-0.4 \pm 0.0$ & 0.25 & 0.50 \\
\hline 8 & Nov. 25, 1995 & $21: 13$ & 2.77 & $7.9 \pm 0.8$ & $8.7 \pm 0.8$ & $8.3 \pm 0.6$ & $0.8 \pm 0.1$ & $0.4 \pm 0.0$ & $-0.5 \pm 0.0$ & 0.25 & 0.50 \\
\hline 9 & Nov. 30, 1995 & 04:49 & 2.56 & $3.6 \pm 0.4$ & $3.0 \pm 0.3$ & $3.1 \pm 0.4$ & $-0.4 \pm 0.0$ & $0.5 \pm 0.0$ & $0.2 \pm 0.0$ & 0.15 & 0.30 \\
\hline 10 & Dec. 03, 1995 & 04:06 & 2.61 & $3.4 \pm 0.3$ & $3.3 \pm 0.3$ & $3.4 \pm 0.3$ & $0.1 \pm 0.0$ & $0.4 \pm 0.0$ & $-0.5 \pm 0.0$ & 0.10 & 0.20 \\
\hline 11 & Dec. 11, 1995 & 00:04 & 2.55 & $2.5 \pm 0.2$ & $2.1 \pm 0.2$ & $2.0 \pm 0.1$ & $-0.2 \pm 0.0$ & $0.2 \pm 0.0$ & $0.2 \pm 0.0$ & 0.20 & 0.40 \\
\hline 12 & Dec. 21, 1995 & $02: 10$ & 2.03 & $2.2 \pm 0.2$ & $2.0 \pm 0.2$ & $2.2 \pm 0.2$ & $0.3 \pm 0.0$ & $0.2 \pm 0.0$ & $-0.2 \pm 0.0$ & 0.10 & 0.20 \\
\hline 13 & Jan. 15, 1996 & 19:03 & 2.28 & $4.3 \pm 0.4$ & $3.9 \pm 0.4$ & $4.0 \pm 0.4$ & $0.0 \pm 0.0$ & $0.4 \pm 0.0$ & $-0.3 \pm 0.0$ & 0.15 & 0.30 \\
\hline 14 & Jan. 16, 1996 & 04:50 & 2.21 & $5.5 \pm 0.4$ & $4.9 \pm 0.5$ & $5.4 \pm 0.4$ & $0.5 \pm 0.0$ & $0.2 \pm 0.0$ & $-0.6 \pm 0.0$ & 0.10 & 0.20 \\
\hline 15 & Jan. 17, 1996 & $20: 12$ & 2.07 & $2.1 \pm 0.2$ & $2.1 \pm 0.2$ & $2.4 \pm 0.2$ & $0.2 \pm 0.0$ & $-0.2 \pm 0.0$ & $0.1 \pm 0.0$ & 0.10 & 0.20 \\
\hline 16 & Feb. 04, 1996 & $19: 23$ & 2.68 & $3.3 \pm 0.3$ & $3.3 \pm 0.3$ & $3.0 \pm 0.2$ & $0.4 \pm 0.0$ & $-0.3 \pm 0.0$ & $-0.4 \pm 0.0$ & 0.10 & 0.20 \\
\hline 17 & Feb. 26, 1996 & $12: 11$ & 2.48 & $7.3 \pm 0.8$ & $7.2 \pm 0.9$ & $7.4 \pm 0.6$ & $0.3 \pm 0.0$ & $0.4 \pm 0.0$ & $-0.6 \pm 0.0$ & 0.15 & 0.30 \\
\hline 18 & Feb. 27, 1996 & 08:50 & 2.74 & $3.9 \pm 0.4$ & $3.8 \pm 0.4$ & $4.0 \pm 0.3$ & $-0.2 \pm 0.0$ & $0.5 \pm 0.0$ & $-0.2 \pm 0.0$ & 0.10 & 0.20 \\
\hline 19 & Mar. 03, 1996 & $20: 58$ & 2.29 & $3.2 \pm 0.3$ & $2.4 \pm 0.3$ & $2.7 \pm 0.3$ & $-0.2 \pm 0.0$ & $0.3 \pm 0.0$ & $0.1 \pm 0.0$ & 0.10 & 0.20 \\
\hline 20 & Mar. 18, 1996 & $14: 18$ & 2.12 & $8.8 \pm 0.6$ & $8.5 \pm 0.6$ & $8.5 \pm 0.7$ & $0.3 \pm 0.0$ & $0.1 \pm 0.0$ & $-0.6 \pm 0.1$ & 0.15 & 0.30 \\
\hline 21 & Apr. 26, 1996 & $22: 45$ & 2.32 & $2.2 \pm 0.2$ & $2.0 \pm 0.2$ & $1.9 \pm 0.2$ & $0.1 \pm 0.0$ & $-0.2 \pm 0.0$ & $-0.3 \pm 0.0$ & 0.10 & 0.20 \\
\hline 22 & Nov. 05, 1996 & 13:06 & 2.50 & $1.7 \pm 0.2$ & $1.5 \pm 0.2$ & $1.7 \pm 0.2$ & $0.0 \pm 0.0$ & $0.5 \pm 0.0$ & $-0.4 \pm 0.0$ & 0.10 & 0.20 \\
\hline 23 & Jun. 10, 1997 & $04: 45$ & 2.17 & $4.3 \pm 0.2$ & $4.2 \pm 0.3$ & $4.3 \pm 0.3$ & $-0.2 \pm 0.0$ & $0.3 \pm 0.0$ & $0.1 \pm 0.0$ & 0.10 & 0.20 \\
\hline 24 & Aug. 03, 1997 & $12: 23$ & 2.66 & $2.1 \pm 0.2$ & $2.0 \pm 0.2$ & $2.0 \pm 0.2$ & $-0.1 \pm 0.0$ & $0.3 \pm 0.0$ & $-0.3 \pm 0.0$ & 0.10 & 0.20 \\
\hline
\end{tabular}

Source time functions were represented as isosceles triangles and the durations ranged from $0.2 \mathrm{~s}$ to $0.5 \mathrm{~s}$. The three diagonal components had similar positive amplitudes for all the events and ranged from 1.5 to $10 \times 10^{11} \mathrm{Nm}$. As illustrated in Table 1, non-diagonal components were negligibly small compared with the diagonal ones.

The relation among diagonal components with error bars ( $2 \sigma$ of normal distribution) is shown in Fig. 4 for all the events. The errors are within $\pm 10 \%$ of each moment tensor components and the ratios of $M_{x x}: M_{y y}: M_{z z}$ are nearly $1: 1: 1$. As shown in the previous section, the estimation of site correction factors has errors. We tried to obtain the moment tensor using all the combinations of the site correction factors within the standard deviation. The ratios of $M_{x x}: M_{y y}: M_{z z}$ of the moment tensors were nearly $1: 1: 1$ except for $1: 1: 1.4$ in the extreme case of the maximum correction factors at ARI (0.62) and HAR (1.65) stations near the sources and minimum ones at KOM (0.59) station far from the sources. Since the three diagonal components express volumetric changes of the source, these results show the first motions of explosion earthquakes represent isotropic expansion.

\section{Discussions}

From the waveform inversion of the first motions of explosion earthquakes, we found that the initial motions are generated by an isotropic expansion. This result is inconsistent with vertical expansion source obtained by previous studies (Iguchi, 1994; Uhira et al., 1995). Particularly, the ratio of horizontal $\left(M_{x x}\right.$ and $\left.M_{y y}\right)$ and vertical dipoles $\left(M_{z z}\right)$ of the moment tensor components are different from the results. To understand these discrepancies we carried out some further tests.

The differences with the results of Iguchi (1994) may be caused by a difference in seismic stations used in the analyses. Here, we added the vertical component of station HIK, located $1.7 \mathrm{~km}$ from the crater, to our analysis. The results of the waveform inversion are shown in Fig. 5(a). The amplitude of the synthetic waveform did not fit the observed data at station HIK, with differences of a factor of 5. Waveforms at station HIK are dominated by higher frequencies $(3.5 \mathrm{~Hz})$ than records of borehole stations which have predominant frequencies of $2 \mathrm{~Hz}$. Next a low-pass filter with a corner frequency of $2 \mathrm{~Hz}$ was applied to the data and synthetics, producing a much better fit. The ratios of the three diagonal components of the moment tensor were almost the same as that obtained by only the borehole seismograms.

One cause of the poor fit between observed and synthetic waveforms filtered at $5 \mathrm{~Hz}$ at station HIK may be because of the site effect. Amplitudes at each station were corrected using amplitude ratios of teleseismic earthquakes with $P$ wave dominant frequencies of $2 \mathrm{~Hz}$. Using the assumption of a flat frequency response, the amplification of higher frequency signals at station HIK may not have been well evaluated. Another possibility is that high-frequency component may be excited by different source mechanism from lowfrequency revealed in this study. The high frequency source may occur at the same source location because of the same 


\section{(a) 5 Hz low-pass}

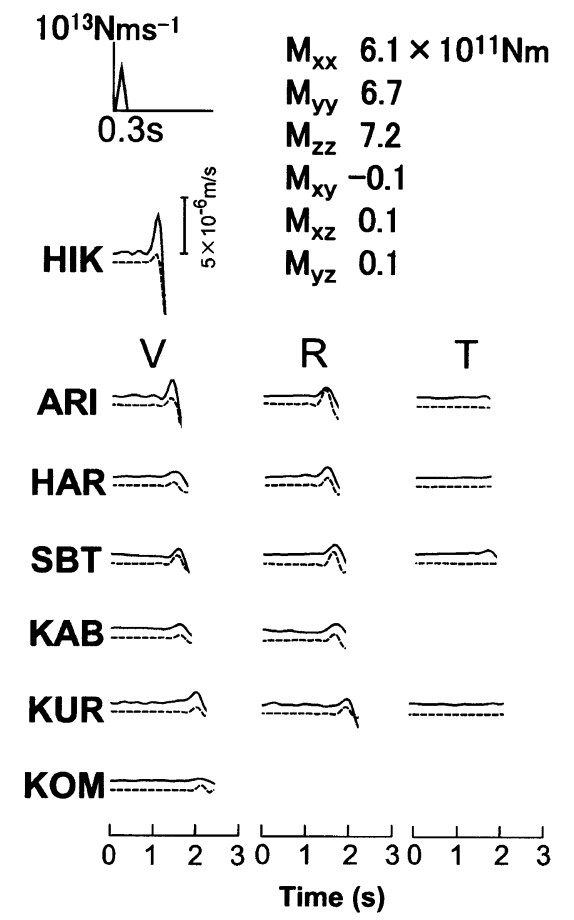

(b) 2 Hz low-pass

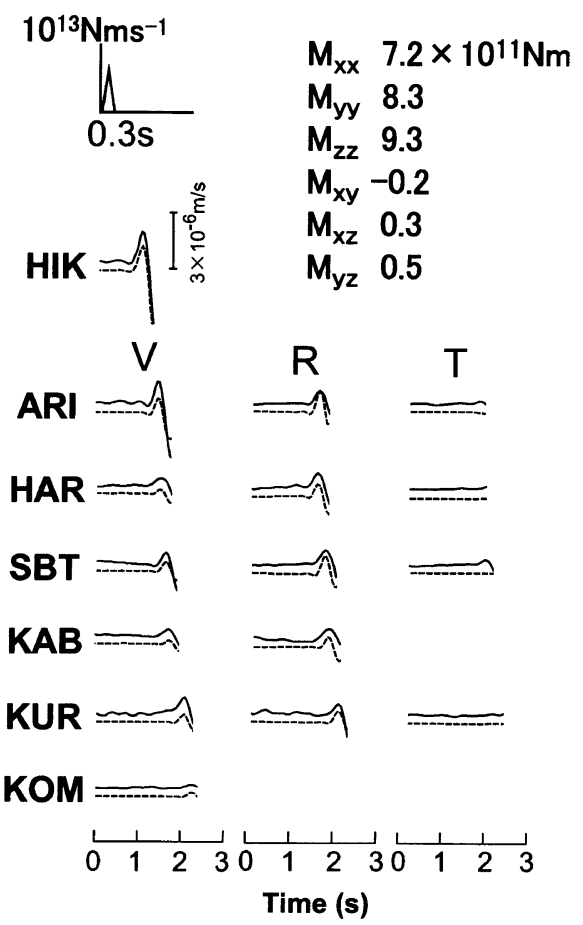

Fig. 5. Results of a waveform inversion for event at 14:18, March 18, 1996 (No. 20) adding vertical data from station HIK. (a) Filtered with low-pass of $5 \mathrm{~Hz}$. (b) Filtered with low-pass of $2 \mathrm{~Hz}$

travel time. Since HIK station is close to the active crater, the high-frequency component, maybe excited by a vertical dipole, is dominant with respect to the other farther stations. The amplitudes of higher-frequency components $(>2 \mathrm{~Hz})$ at station HIK are larger than amplitudes of the other borehole stations by 1 to 2 orders of magnitude. The high-frequency component may be attenuated at distant borehole stations with $Q$ value of around 10. Aki (1984) showed that the source mechanism of short-period $P$-waves is different from that of long-period $P$-waves at Mammoth Lakes. Anyway, it is concluded that source mechanism of explosion earthquake with frequency lower than $2 \mathrm{~Hz}$ is an isotropic expansion.

Uhira et al. (1995) showed that the ratios of the $M_{x x}, M_{y y}$, and $M_{z z}$ components of the moment tensor of the initial phase were nearly $1: 1: 3$. Here, we attempted to obtain the moment tensor by using two surface seismometers at HAR and NOJ, as shown in Fig. 6. The $M_{z z}$ component of the moment tensor was larger than the $M_{x x}$ and $M_{y y}$ components. It is thought that the dominance of $M_{z z}$ may be caused by the poor fit of synthetic waveforms to observed data because of the time lag of the radial components.

Intensity of explosion earthquakes should be also considered as a factor for explaining differences with previous studies. The maximum amplitudes (peak-to-peak) of explosion earthquakes used in Iguchi (1994) ranged from 77.5 to 115 $\mu \mathrm{m}$ in the records of a displacement-type seismometer installed at station HAR, and Uhira et al. (1995) analyzed explosion earthquakes with maximum amplitude of $80 \mu \mathrm{m}$. In this study, we analyzed explosion earthquakes with maximum amplitude ranging from $17.5 \mu \mathrm{m}$ to $65 \mu \mathrm{m}$, which are
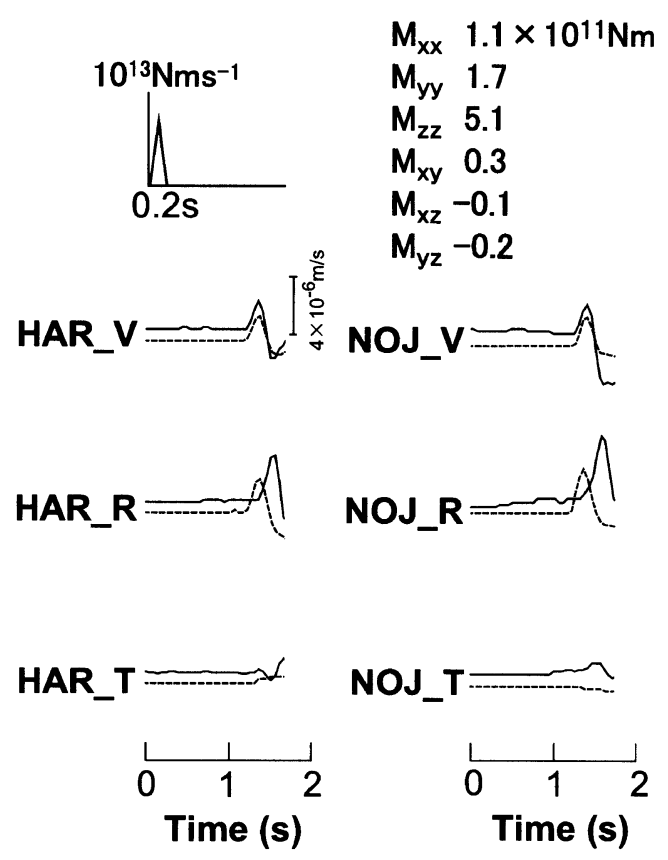

Fig. 6. A result of waveform inversion for event at 04:45, June 10, 1997 (No. 23) using surface seismograms at stations HAR and NOJ. The radial components of the synthetic waveforms do not fit the observed at the onset of the first motion. 


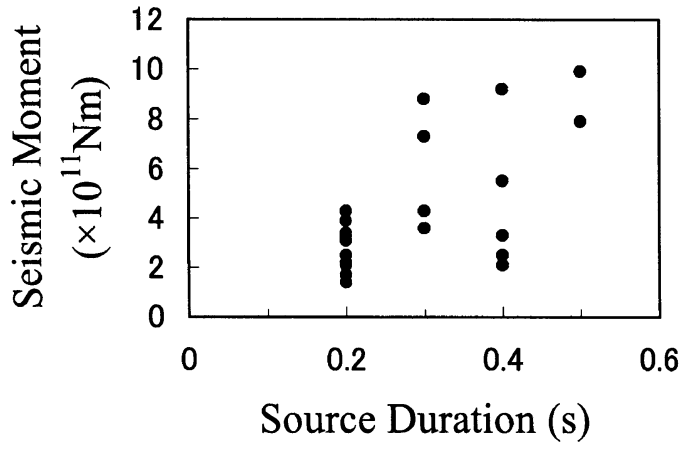

Fig. 7. Relation between the source duration and the seismic moment of explosion earthquakes

smaller than events used in the previous studies.

The source time functions were represented as isosceles triangles and the durations ranged from $0.2 \mathrm{~s}$ to $0.5 \mathrm{~s}$ as shown in Table 1. We examined relation of source durations and the seismic moments (Fig. 7). Clear relation was not found in the limited range of $10^{11} \sim 10^{12} \mathrm{Nm}$. In this study we treated explosion earthquakes with rather small seismic moment, but there is our intention to estimate in more detail source time function of explosion earthquakes with larger seismic moment. We will analyze larger explosion earthquakes to examine dependence of mechanisms and source duration on magnitude of explosion earthquakes.

\section{Conclusions}

We evaluated the moment tensor of the first motion of 24 explosion earthquakes observed by borehole seismometers. The first motions of explosion earthquakes were dominated by three dipoles $\left(M_{x x}, M_{y y}\right.$, and $\left.M_{z z}\right)$ with almost the same value. Durations of triangular source time function ranged from $0.2 \mathrm{~s}$ to $0.5 \mathrm{~s}$. It is concluded that explosion earthquakes are initiated by an isotropic expansion.

Acknowledgments. We greatly thank the staff members of Sakurajima Volcano Research Center, Disaster Prevention Research Institute of Kyoto University, for acquiring data. Thanks are extended to Prof. Kazuo Tanaka and Dr. Masahiro Kosuga of Hirosaki
University for giving the opportunity and technical support of the current study. Reading and comments by Prof. Jim J. Mori of Research Center of Earthquake Prediction, DPRI, Kyoto Univ. and two anonymous reviewers were very helpful to revise the manuscript.

\section{References}

Aki, K., Evidence for magma intrusion during the Mammoth Lakes earthquakes of May 1980 and implications of the absence of volcanic (harmonic) tremor, J. Geophys. Res., 89, 7689-7696, 1984.

Bouchon, M., A simple method to calculate Green's functions for elastic layered media, Bull. Seismol. Soc. Am., 71, 959-971, 1981.

Iguchi, M., A vertical expansion source model for the mechanisms of earthquakes originated in the magma conduit of an andesitic volcano: Sakurajima, Japan, Bull. Volcanol. Soc. Jpn., 39, 49-67, 1994.

Iguchi, M., Source mechanisms of volcanic earthquakes and tremors and their field of origin, Bull. Volcanol. Soc. Jpn., 40, S47-S57, 1995 (in Japanese).

Ishihara, K., Geophysical evidences on the existence of magma reservoir and conduit at Sakurajima volcano, Japan, Ann. Disast. Prev. Res. Inst. Kyoto Univ., 31B-1, 59-73, 1988 (in Japanese with English abstract).

Kennett, B. L. N. and N. J. Kerry, Seismic waves in a stratified half space, Geophys. J. R. Astron. Soc., 57, 557-583, 1979.

Kikuchi, M. and H. Kanamori, Inversion of complex body waves-III, Bull. Seismol. Soc. Am., 81, 2335-2350, 1991.

Minakami, T., Seismology and volcanoes in Japan, in Physical Volcanology, edited by L. Civetta, P. Gasparini, G. Luongo, and A. Rapolla, pp. 1-27, Elsevier, 1974.

Nishi, K., On the explosion earthquake of Sakurajima volcano, Ann. Disast. Prev. Res. Inst. Kyoto Univ., 19B, 69-73, 1976 (in Japanese with English abstract).

Sakurajima Volcano Research Center, Disaster Prevention Research Institute, Kyoto University, Volcanic activity of Sakurajima volcano (February-May, 1999), Rep. Coord. Comm. Prediction Volcanic Eruption, 74, 111-117, 1999 (in Japanese).

Takeo, M., Near-field synthetic seismograms taking into account of the effects of anelasticity-The effects of anelastic attenuation on seismograms caused by a sedimentary layer, Pap. Meteorol. Geophys., 36, 245-257, 1985 (in Japanese with English abstract).

Uhira, K. and M. Takeo, The source of explosive eruption of Sakurajima volcano, Japan, J. Geophys. Res., 99, 17775-17789, 1994.

Uhira, K., S. Ikeda, and M. Takeo, Source process of explosion earthquakes deduced from short-period records at Sakurajima volcano, Bull. Volcanol. Soc. Jpn., 40, 295-310, 1995.

Yamasato, H., Distribution of the initial motions of explosion earthquakes at Sakurajima volcano, Bull. Volcanol. Soc. Jpn., 32, 289-300, 1987 (in Japanese with English abstract).

T. Tameguri (e-mail: tamekuri@svo.dpri.kyoto-u.ac.jp), M. Iguchi, and K. Ishihara 